計算値 C 48.21, H 2.23, N 12.50, 笑驗值 C 47.77, H 2.56, N 12.35. (ii) 6-Chlor-5-nitrochinolin-Noxyd $(0.9 \mathrm{~g})$ (B) アル゙ゥリ性クロロホルム抽出 $0.4 \mathrm{~g}$. (i) 6-Chlor-5-nitrochinolin (Fp $\left.129^{\circ}\right)(0.1 \mathrm{~g})$ 。 (ii) 6-Chlor-5-nitrochinolin- $N$-oxyd $(0.2 \mathrm{~g})$.

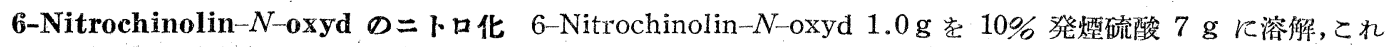

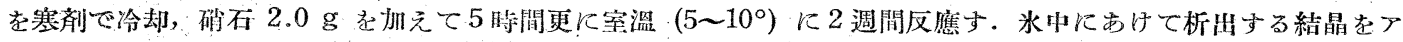
セトンより再結, 黄色杜狀晶 $Z \mathrm{p} 218^{\circ}, 4,6$-Dinitrochinolin- $N$-oxyd ${ }^{1)} 0.9 \mathrm{~g}$ を得. これを塩酸と処理すれ代 1 個のニトロ基はクロル基に置換し得る。 $\mathrm{C}_{9} \mathrm{H}_{5} \mathrm{~N}_{3} \mathrm{O}_{5}$ 計算值 $\mathrm{C} 45.96, \mathrm{H} 2.14, \mathrm{~N} 17.87$, 实驗値 $\mathrm{C} 45.99$, H 2.72, N 17.49 .

\title{
Summary
}

The effect of the $N$-oxide group in quinoline- $N$-oxide is more striking at a higher temperature. Nitration of 6-methyl-, 6-chloro-, and 6-bromo-quinolines at a low temperature gives 5-nitro compounds, while that at a higher temperature gives 4-nitro compounds. Due to the effect of the methoxyl group, 6-methoxyquinoline- $N$-oxide does not yield a 4-nitro compound. 4-Nitro comound is quantitatively obtained from 6nitroquinoline- $N$-oxide by nitration at a low temperature.

(Received December 20, 1950)

\section{3. 秋谷七郎，手島節三，原田博富：和ごのり寒天質の化学的研究}

Shichiro Akiya,* Setsuzo Tejima** and Hirotomi Harada*: Studies on Agar-agar.

(Pharmaceutical Institute, Medical Faculty, University of Tokyo* and Kumamoto College of Pharmacy**)

石花荣 (Gelidium Amansii Lamx.) 寒天貿の化学構造に関しては, 近年に至り国內では荒本長次1), 海外では E. J. V. Percival2) 等の卓越せる研究に見るべきものがある.しかし石花荣と同じ紅藻類 (Rhodophyceae) に 属する 怙ごのり (Gracilaria Confervoides Grev.) の寒天質に関する研究は極めて少く，著者等は柳川鉄之助 3)の啹告を見るのみであつた。著者等は抽のり寒天質の化学構造は石花荣寒天質のそれと同じであるか否かを 解明したいと思い,括ごのりより製作した寒天製品（天素吕）より寒天筫を精製し化学的研究を行つているが,若干

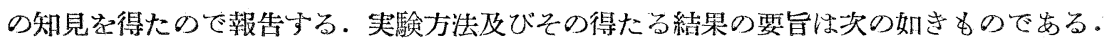

1) 寒天質の精製4) 湯抽出液を濃縮し有機溶媒で沈澱する力法と熱湯抽出液を涷結する力法走朋いた。後者は古 くより巷間でする寒天製法5)の常法で女るが実験空でも極めて良好な結果を得た２）寒天質の分析 呿ごのり寒

第 1 表 各種寒天質, 硫酸含量

(i) 柳川鉄之助（大阪工業試驗所報告，14 回 5 号 (1938).)

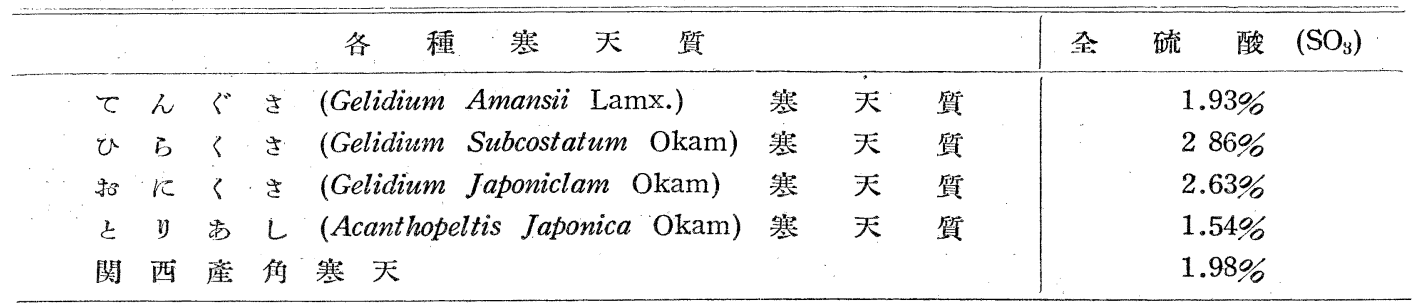

* Motofuji-cho, Bunkyo-ku, Tokyo. **ōe-machi, Kumamoto.

1) 荒木：(第 1 報一第 14 報) 日化 58 (1937) - 65 (1944). 荒木：化学の領域 3 (5), 2 (1949).

2) E. J. V. Percival : J. Chem. Soc. 1937, 1615, 1939, 1844.

3) 柳川：大阪工業試驗所報告第11回第14号, 第17回第 6 号 (1936).

4) 勝田泰：衞生試報 37, 117 (1930). a)千葉縣東葛飾郡行德町稻荷木（天素糊料工業所製品） 
(ii) 荒术長焁 (化 学 0 領 域 3 (5), 2 (1949). )

\begin{tabular}{|c|c|c|c|c|c|c|c|c|}
\hline & & 種 & 天 & 質 & 硫 & 黃 (S) & 全 硫 & 酸 $\left(\mathrm{SO}_{3}\right)$ \\
\hline$\tau$ & ん & ぐ さ 寒 天 & 質 & & & $0.64 \%$ & & - \\
\hline 元 & ど & (Campylaephora & Hypneaides & $\mathrm{J} . \mathrm{Ag}$ ) 寒 天 質 & & $1.2 \%$ & & $3.1 \%$ \\
\hline ¿ & $y$ & 通 乙 寒 天 & 質 & & & $0.75 \%$ & & $2.0 \%$ \\
\hline v & b & くさ寒 天 & 質 & & & $0.95 \%$ & & $2.6 \%$ \\
\hline
\end{tabular}

天質の分析値を石花荣寒天質のそれ6) と比較して見ると,全還元糖，galactose，灰分等は大美ないが硫酸の含量が 著しく少い。硫酸 (若しくは硫黄)含量について,物ごのり寒天質と從來交献に発表された市販の寒天文は特定の 海草から作つた塞天質の分析值を比較して見ると第 1 表の如くである.即ち原料海草により硫酸含量は異るが通 常 1.5 乃至 $3 \%$ 有するが著者等の括ごのり塞天質は僅か $0.57 \%$ である．3）寒天質を硫酸により加水分解し た. 此の際,酸濃度と加熱時間を変化した場合の生成した還元糖の消長を還元力により檢した。その結果石花荣寒 天質のそれに7）類似する事を知つた.4）寒天資より $d$-galactose を結晶狀に分離し確認した。 5) 寒天質のアセ チル化体を作つた。種々条件を变えてア七チル化しアさチ几基つ含量起測定したが 36 乃至 $37 \%$ 以上に上昇せ ず，アセチル含量及び性狀は石花荣塞天質のそれに゙）類似する，6）アセチル寒天質をデメチル硫酸乞 $\mathrm{NaOH}$ メチル化せるも 6 回反覆するもメトオキシル含量 $30 \%$ 以上に上昇せず， $\mathrm{CH}_{3} \mathrm{I}$ と $\mathrm{Ag}_{2} \mathrm{O}$ によるメチル化を併用 したがメ小オキシル含量は增加せず，石花荣寒天質に於ける荒落の結果9と異り本物質を完全にメルル化する事

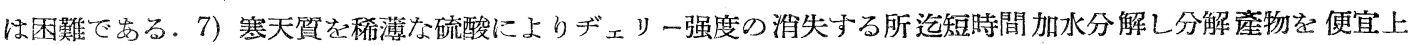
$\alpha ， \beta, \gamma, \delta, \lambda$ の種に分離した。此等はそれぞれ單一な物でないと思われ更に研究を続ける予定であるが，分 離物の還元力, 全澴元糖, galactose 及び硫酸を定量しアセタートにして沃素價より本均分子量起求めた. 石花 荣寒天質の部分的加水分解產物の研究には高橋栄治の研究10) が安る. 氏は寒天質を熱湯で加圧加水分解し hydrate-Kanten $\delta$ 及び hydrate-Kanten $\lambda$ のつに分けているが，著者等の分解產物と比較して見ると著者の $\alpha$ はその性狀は hydrate-Kantn $\delta$ に極めて類似する。

\section{実験 の 部}

1) 寒天椞の調製 (a) 有機溶媒に依る沈澱法 天素 $30 \mathrm{~g}$ 亿水 $1500 \mathrm{cc}$ を加光還流冷却器を附し沸騰水浴上 3 時間加熱する。先ず布で滤過し次いで濾紙を㙋つた大きな Büchner 漏斗を用い吸滤する。濾液は水浴上で $1 / 10$

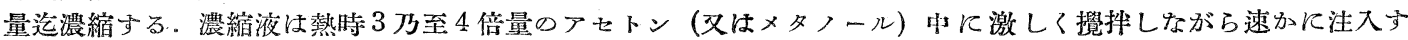
る. 1 夜放置し沈澱せる白色粉未狀の寒天質を布で圧濾し風乾し硫酸を入れを翰燥器中几保存する.收量 $12 \mathrm{~g}$. 沈溊剂にはアセトンを用いた方がメタノールを用いた時より沈澱の分離が完全で滤過も容易でまる。メタノール を用いると一部ゼリ一狀となり濾過も困難である。

（b）凍結法に依る精製法（a）法に依つて製した天素熱湯抽出濾渡を濃縮する事無く大きなビーカース入れ放 置すれば冷却すると從い固化する。常溫になつた後一 $10^{\circ}$ の製氷機中に 1 夜放置すれば全部凍結する。乙れて少量

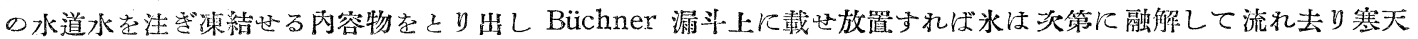

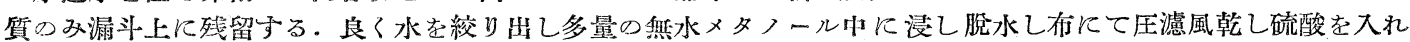
た乾燥器山に保存する。收量 $14 \mathrm{~g}$. 2) 寒天啠の分析 (a) 風乾物の水分 試料 $2.1310 \mathrm{~g}$. 乾燥後の減量 0.3145 $\mathrm{g}$, 水分\% 14.76. (b) 風乾物の灰分 試料 $0.4930 \mathrm{~g}$. 熱灼後の残量 $0.0175 \mathrm{~g}$, 灰分 \% 3.55 . 乾物の galactose（粘液酸法（Tollens 法） K依る） (i) 試料 $1.1090 \mathrm{~g}$.粘液酸 $0.2410 \mathrm{~g}$. galactose \% $\frac{0.2410 \times 1.33 \times 100}{1.1090}=28.90$ (ii) 試料 $1.2615 \mathrm{~g}$.粘液酸 $0.2780 \mathrm{~g}$ galactose $\% \frac{0.2780 \times 1.33 \times 100}{1.2615}=29.31$ (d) 風乾物の pentose 定量 ${ }^{13)}$ Tollens 法に依り pentose turfurol phloroglucide として定量試料 2.9610 $\mathrm{g}$, furfuro! phloroglucide $0.0305 \mathrm{~g}$, pentose $\% \frac{(0.0305+0.0052) \times 1.0075 \times 100}{2.9610}=1.22 \quad$ (e) 無水物の全 還元糖 R. Willstätter, L. Zechmeister ${ }^{11)}$ の方法に依る.試料 $50.65 \mathrm{mg}$.Bertrand 法に依る galactose 37.0 $\mathrm{mg}$, 余還元糖 (galactose として) 73.05\% (f) 無水物の硫黄 S. Liebig 法に從い約 $1 \mathrm{~g}$ の試料を硝石と $\mathrm{KOH}$ の混合物 $(1: 7) 8 \mathrm{~g}$ で酸化し常法に從い $\mathrm{BaSO}_{4}$ として科量した。試料 $1.0643 \mathrm{~g} . \mathrm{BaSO}_{4} 0.0192 \mathrm{~g}$.

5) 朝比奈泰彥：本誌 48，383 (1928)。6) 荒木：日化 58, $1214(1937) ， 7)$ 荒木：日化 58, 1214 (1937).

8) 荒条：日化 58, 1338 (1937)。 9) 荒木：日化 58 1354 (1937)。 10) 高橋栄治：農化 7, 702 (1931) 8 659, 1259 (1937). 11) R. Willstätter, L. Leichmeister: Ber. 462401 (1913). 
S. $0.25 \% \mathrm{SO}_{3} 0.62 \%(\mathrm{~g})$ 無水物の硫酸 舆水物 0.5 乃至 $1 \mathrm{~g}$ を 50 倍量の $\mathrm{n}-\mathrm{HCl}$ を加え還流冷却器を附し 初め水浴上で加熱する。溶解してから直火で 2 時閒加熱し滤液を約 15 倍に稀釈し $5 \% \mathrm{BaCl}_{2}$ の過剩を加え $\mathrm{BaSO}_{4}$ として科量する.(i) 試料 $0.4929 \mathrm{~g} . \mathrm{BaSO}_{4} 0.0124 \mathrm{~g}, \mathrm{SO}_{3} \% 0.62$ (ii) 試料 $0.5338 \mathrm{~g} . \mathrm{BaSO}_{4} 0.0079 \mathrm{~g}, \mathrm{SO}_{3} \% 0$. 51 (iii) 試料 $1.0746 \mathrm{~g} \mathrm{BaSO}_{4} 0.0177 \mathrm{~g}, \mathrm{SO}_{3} \% 0.57$, 平均 $0.57 \%$.

3）寒天質の硫酸分解 寒天質 $10 \mathrm{~g}$ 凡 $200 \mathrm{cc} \odot \mathrm{n}-\mathrm{H}_{2} \mathrm{SO}_{4}, \mathrm{n} / 10 \mathrm{H}_{2} \mathrm{SO}_{4}, \mathrm{n} / 50 \mathrm{H}_{2} \mathrm{SO}_{4}$, 及び $\mathrm{n} / 100 \mathrm{H}_{2} \mathrm{SO}_{4}$ をそれ ぞれ加え沸騰水浴上で還流冷却器を附し加熱し一定時閒後その $10 \mathrm{cc}$ を取り対雇する濃度の $\mathrm{Na}_{2} \mathrm{CO}_{3} 10 \mathrm{cc}$ で中和 しその $5 \mathrm{cc}$ を取り Bertrand 法で還元榶を定量し galactose として算定した。その結果を第 2 表に表示する。

第 2 表 各種濃度の硫酸で加熱せる時の還元力の消長

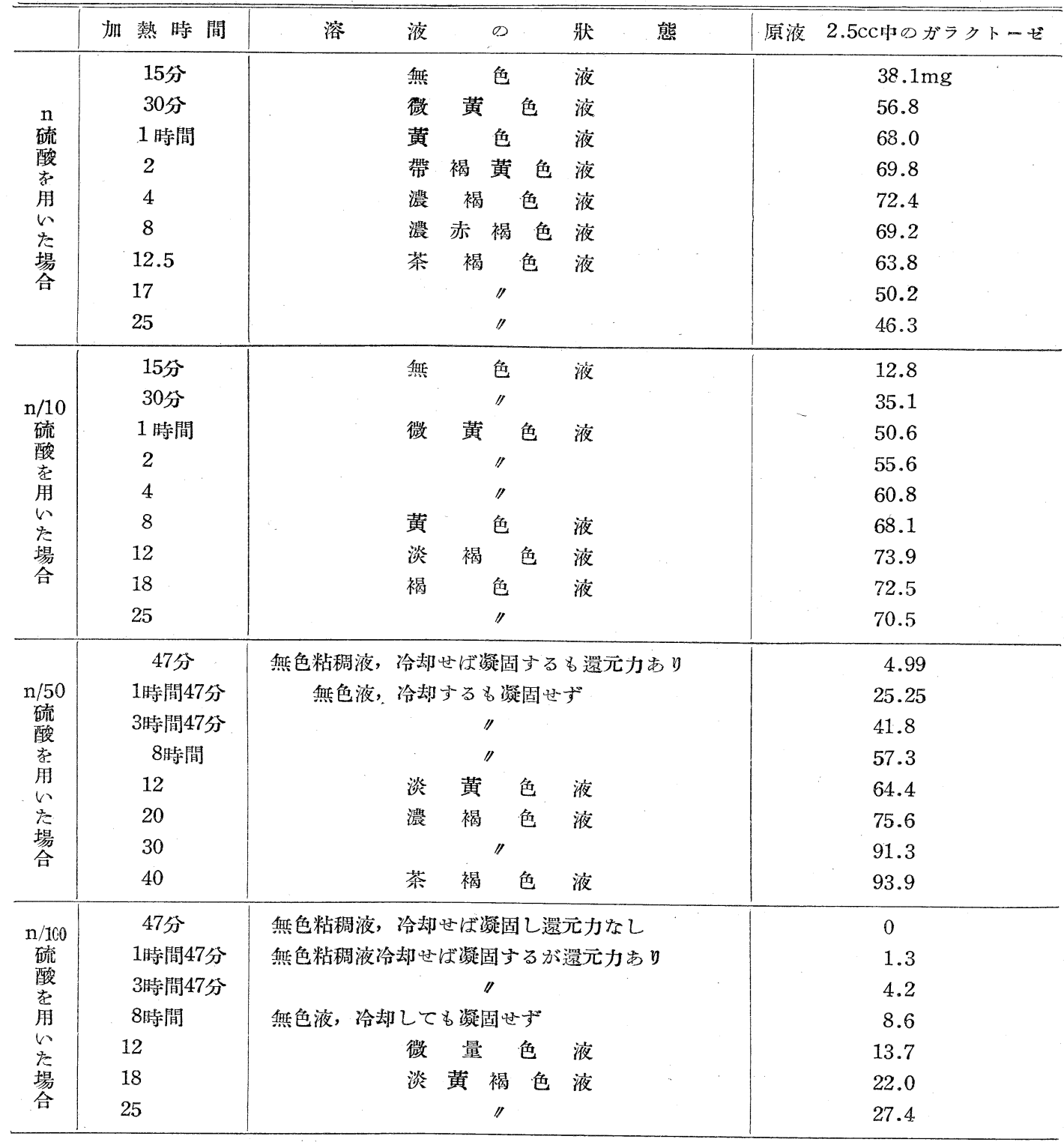

4) $d$-Galactose の分離 寒天質 $15 \mathrm{~g}$ K $1 n-\mathrm{H}_{2} \mathrm{SO}_{4} 200 \mathrm{cc}$ を加え還流冷却器を附し水浴上 6 時閒加熱する. 冷後生成せるフーマス質を除き滤液を $\mathrm{Ba}(\mathrm{OH})_{2}$ と $\mathrm{BaCO}_{3}$ で中和し $\mathrm{BaSO}_{4}$ を除去しを滤液を脱色後、1/10 量に 減圧濃縮し 10 倍容の $96 \%$ アルコールを㸝1夜放置して生成する沈澱物を除去した滤液を $1 / 15$ 量に減圧濃縮

13) 河出書房 : "化学实驗学" II, 11, 181, 191. 
し2 倍量の笽水メタノールを加え冷所に放置すると絬晶が析出する.收量 $2.5 \mathrm{~g}$. 母液を䟴縮し更に $0.6 \mathrm{~g}$ 計 3 . Ig の結晶を得, 熱メタノールょり 2 回再結晶し $\mathrm{mp} 167^{\circ}$ (補正). [a $]_{\mathrm{D}}^{20}+80.8^{\circ}$. d-galactose と混融するも融 点降下せず, 更に次の試驗を行う. (a) galactosazone の生成 分離した結晶 $0.5 \mathrm{~g}$ を水 $10 \mathrm{cc}$ 亿溶解し $2 \mathrm{~g}$ の塩酸フェニルヒドラチンと $3 \mathrm{~g}$ の結晶醋酸曹達を加え加熱し黃色針狀の osazone 得, 熱アルコールより 再結, $\operatorname{mp~} 200^{\circ}$ (補正), $d$-galactose ๖り作つた osazone と混融するむ融点降下せず. (b) 粘液酸の生成分離 した結晶 $0.5 \mathrm{~g}$ と比重 1.15 ○ $\mathrm{HNO}_{3} 60 \mathrm{cc}$ を加え水浴上 $20 \mathrm{cc}$ 迄濃縮し 1 夜放置後析出せる白色結晶を滤過 し水, アルコール, エーテルで洗滌した. $\mathrm{mp} 213^{\circ}$ (補正). 粘液酸さ混融するす降下せず。

以上の結果から分離した結晶は $d$-galactose でする事を確認した。

5) 寒天質のアセチル化 (a) アセチル寒天質の製法 2) (b) の方法で作つた寒天質を細断してその $1 \mathrm{~g}$ を $1 \mathrm{cc}$

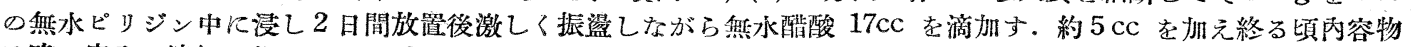
は略々完全に溶解し均一となる.24 時閒放置し多量の水水中に注入する. 沈澱物を吸湽し水, メタール及びェー テルで洗い乾燥する。次いで 30 倍のアセトンに溶解し滤液に同量のエーテルを加え沈澱せるアセチル寒天質を吸 滤乾燥す。性狀は荒木氏の $\mathrm{CHCl}_{3}$ 可溶性アセチル寒天質8) のそれに類似しアセトン $\mathrm{CHCI}_{3}$ に溶解し粘性の强

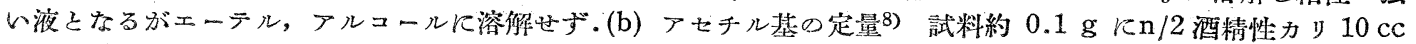
を加え $250 \mathrm{cc}$ の共栓付フラスコの中で時々振盪しつつ24 時間放置後 $7 \mathrm{cc}$ の水で稀釈しフェノールフタレインを 指示薬こして $\mathrm{n} / 10 \mathrm{HCI}$ で過剩の $\mathrm{KOH}$ を逆測する. のアセチル基量 (i) $80 \%$ ピリヂンを用いた場合 製法の骨子は (a) の通りであるが無水ピリヂンの代りに80

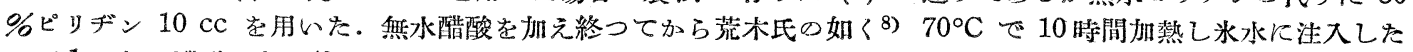
のが 1 , 無水醋酸を加え終つて室溫で 24 時閒放置せるものが 2 , 同じく 48 時間放置せるるのが 3 , 同じく 72 時間放置せるるのが 4 である。結果は第而表の如し. (ii) 無水醋酸の量を变化した場合 溶媒は艌水ピリヂンを 用い無水醌酸量を $5 \mathrm{cc}, 10 \mathrm{cc}, 15 \mathrm{cc}, 20 \mathrm{cc}$, 之変化した $(5,6,7,8)$. 無醋を加え終つて 24 時間室溫に放置し て承水中に注入する.結果は第IV表の如し.(iii) 反應時間を変化した場合 溶媒は無水ピリヂンを用い無醋 $17 \mathrm{cc}$ を加え終つて 24 時間, 48 時間, 72 特間室溫に放置し $(9,10,11)$ 然る後水水中に注入した結果は第 V表の如し. (iv) アセチル化を 2 回繰り返した場合 2 及 9 を原料さし (a) の方法で 2 回アセチル化した。何水高無水ピリ ヂンを溶媒さし反應時間は 24 時間である. 結果は第IX表の如し.

6) 寒天質のメチル化”（i）第 1 回×チル化 5) (a) に依り製したアセチル寒天 $10 \mathrm{~g}$ を水銀攪汼器をつけた

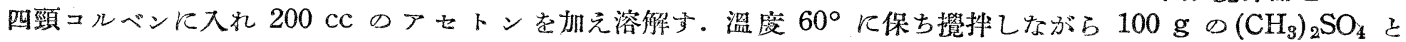
$200 \mathrm{cc} \infty 30 \% \mathrm{NaOH}$ を 2 時間を要し同時に加え終る如く滴加する. 滴加終了後,倫同溫度に 1 時間覴拌を続け る。徐々に溫度を上げアセトンを溜去し浴溫 $100^{\circ}$ になてから更に 1 時閒攪拌する。メチル寒天質は煎餅狀さ なり表面に浮ぶ、沸湯で洗滌し速かに存濾する。吸湿性でする.收量 $8 \mathrm{~g}$ (ii) 第 2 回×チル化 (i) $8 \mathrm{~g}$ 光同漛 操置操作でメチル化する。溶媒には $80 \%$ とトン $200 \mathrm{cc}$ を用いる。メチル化物は白色細粒狀をなる。 (iii) 第 3 回乃至第 6 回×チル化 25 倍の $80 \%$ セトンに溶解し 12.5 倍の $\left(\mathrm{CH}_{3}\right)_{2} \mathrm{SO}_{4}$ とその 2 倍容の $30 \% \mathrm{NaOH}$ でメチル化する. (iv) 6 回×チル化物を $\mathrm{CH}_{3} \mathrm{I}$ \& $\mathrm{Ag}_{2} \mathrm{O}$ でメチル化上記 6 回メチル化物 $2 \mathrm{~g}$ V $20 \mathrm{~g} の \mathrm{CH}_{3} \mathrm{I}$

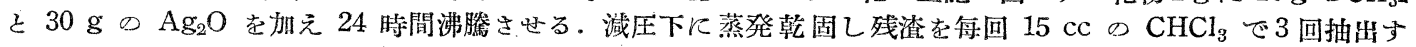

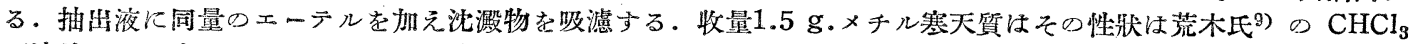
可溶性×チル寒天質に類似し冾水に溶けるが熱湯に溶解せず. $\mathrm{CHCl}_{3}$, 氷醋酸に易溶, ェーテルに不溶. (v) メト オキシル基定量 Halbmikro の Zeisel 法に依る. 方法及裝置は落合, 津田：有機微量小量分析法 241 頁 (科学 書院）結果は第倓表の如し.

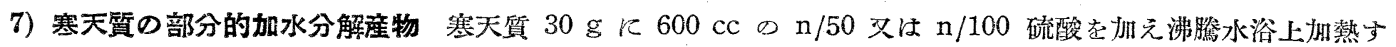

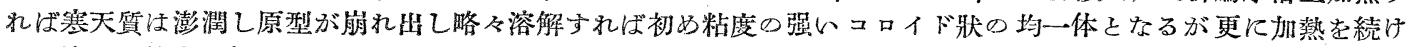
ると速かに粘度は低下し還元力は增加し略々透明な液となるが整時にして再び絮狀の白色沈澱が現われ始める。

(a) 分解產物の分離法 分解產物の分離操作を一括表示すれば第卭表の如し. そして前後 7 回の分離產物の收 量は第IX表の如し。

（b）各分解產物の性狀及分析值 (i) 性狀 a は熱湯に溶解するも冷時糊狀となり析出する. 50 倍の熱湯に溶 解し冷却析出さ还て精製しメタノールで完全に㧤水し粉碎すれば白色粉末るなる.ピリヂンにも温時溶解するが

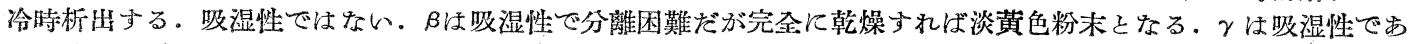
るが完全に㧤水すれば白色粉末さなる。 なる.入は極めて吸湿性强く斡燥器から出せば飴狀となる. 淡黃色乃至褐色粉末 (ii) 分析 Bertrand 法で定 量し galactose こして計算した還元力. Tollens 法に依る galactose, Willstätter 法に依る全還元糖及び硫酸 を定量した。絬果は第 $\mathrm{X}$ 表に一括して示す. $\quad$ (c) 寒天質及部分的分解產物の分子量 (i) $a, \gamma, \delta, \lambda の>$ チル化 $\alpha_{9} \gamma_{3} \delta_{3} \lambda_{3}$ の各 $1 \mathrm{~g}$ を $10 \mathrm{cc}$ のピリヂンに溶解し無水醋酸 $10 \mathrm{cc}$ を滴加乙 48 時間室溫に放置後水水中 に注入する. 白色粉末狀のアセタートを吸濾水洗後乾燥する.15 倍のアセトンに溶解しアセトンの 5 倍量のメタ ノールを加え1夜放置後沈澱物を吸濾, エーテルで洗涤後乾燥する， $\alpha, \gamma, \delta, \lambda$ 何れのアセタートもアセトン

12) M. Bergmann : Ber. 63, 316 (1930). 
$\mathrm{CHCl}_{3}$, ピリデンに易溶なるもェーテル,ベンゾール,アルュールに殆ど溶解せず.(ii) 沃度價测定及び分子量測定 M. Bergmann 氏法 ${ }^{12)}$ に依りアセタートの一定量の酸化に矮した $\mathrm{n} / 10 \mathrm{I}$ 溶液の量よ $り$ 試料 $1 \mathrm{~g}$ に対する $\mathrm{n} / 10$

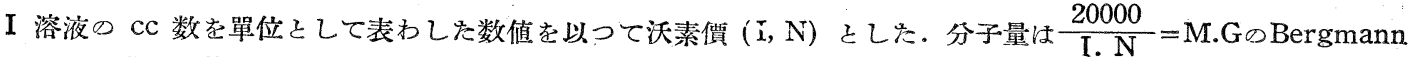
の法則に從い計算した。結果は第 XI 表に一括して表示する.

東京大学医学部薬学科 熊本薬学專門学校

第 III 表

\begin{tabular}{|c|c|c|c|c|c|c|c|c|}
\hline 製 & 造 & 件 & \multicolumn{6}{|c|}{ アセチル基定量 } \\
\hline 番 号 & \multicolumn{2}{|c|}{ 反岿溫度及び時間 } & 試 料 $\mathrm{g}$ & $\mid \begin{array}{l}\text { アルコール性| } \\
\text { n/2-KOH }\end{array}$ & $\mathrm{n} / 10 \mathrm{HClcc}$ & $\left|\begin{array}{l}\text { 省費せる } \mathrm{n} / 10 \\
\mathrm{KOH} \text { cc }\end{array}\right|$ & $\mathrm{CH}_{3} \mathrm{CO} \mathrm{mg}$ & $\mathrm{CH}_{3} \mathrm{CO} \%$ \\
\hline 1 & \multicolumn{2}{|c|}{$70^{\circ} 10$ 時間 } & 0.1350 & \multirow{2}{*}{$\begin{array}{c}\text { F. } 0.891 \\
10 \\
\text { F. } 0.891 \\
10\end{array}$} & F. $\begin{array}{r}1.160 \\
28.44\end{array}$ & 11.56 & 49.7 & 36.82 \\
\hline 2 & & 24 時間 & 0.2145 & & F. $\begin{array}{r}1.160 \\
23.18\end{array}$ & 17.66 & 75.9 & 35.40 \\
\hline 3 & & 48 時間 & 0.0924 & F. 0.891 & F. $\begin{array}{l}1.091 \\
33.67\end{array}$ & 7.82 & 33.6 & 36.40 \\
\hline 4 & $25^{\circ}$ & 72 時間. & 0.1040 & $\begin{array}{c}\text { F. } 0.891 \\
10\end{array}$ & F. $\begin{array}{r}1.160 \\
30.71\end{array}$ & 8.93 & 38.4 & 36.92 \\
\hline & & & & 第 & 表 & & & \\
\hline
\end{tabular}

\begin{tabular}{|c|c|c|c|c|c|c|c|c|c|}
\hline 製 & 造 & $\varepsilon$ & 件 & & & セ チ & 儿基定量 & & \\
\hline 番 号 & 無 水 & 醋 & 酸 cc & 試 料 $\mathrm{g}$ & $\mid \begin{array}{l}\text { アルュール性 } \\
\mathrm{n} / 2 \text {-KOHcc }\end{array}$ & $\mathrm{n} / 10-\mathrm{HClcc}$ & $\left|\begin{array}{l}\text { 消費せる } \mathrm{n} / 10 \\
\mathrm{KOHcc}\end{array}\right|$ & $\mathrm{CH}_{3} \mathrm{CO} \mathrm{mg}$ & $\mathrm{CH}_{3} \mathrm{CO} \%$ \\
\hline 5 & & 5 & & 0.1030 & $\begin{array}{c}\text { F. } 0.891 \\
10\end{array}$ & F. $\begin{array}{l}1.160 \\
31.56\end{array}$ & 7.94 & 34.1 & 33.15 \\
\hline 6 & & 10 & & 0.1095 & $\begin{array}{c}\text { F. } 0.891 \\
10\end{array}$ & F. $\begin{array}{l}1.160 \\
30.38\end{array}$ & 9.31 & 40.0 & 36.56 \\
\hline 7 & & 15 & & 0.0995 & $\begin{array}{c}0.891 \\
10\end{array}$ & F. $\begin{array}{r}1.160 \\
31.18\end{array}$ & 8.38 & 36.0 & 36.22 \\
\hline 8 & & 20 & & 0.0935 & $\begin{array}{c}\text { F. } 0.891 \\
10\end{array}$ & F. $\begin{array}{r}1.160 \\
31.50\end{array}$ & 8.01 & 34.4 & 36.84 \\
\hline
\end{tabular}

\begin{tabular}{|c|c|c|c|c|c|c|c|}
\hline 製 & 造 条：作 & \multicolumn{6}{|c|}{$r$} \\
\hline 番 号 & 反應時間（時間） & 試 料 $g$ & $\mid \begin{array}{l}\text { アルュール性 } \\
\mathrm{n} / 2-\mathrm{KOHcc}\end{array}$ & $\mathrm{n} / 10-\mathrm{HClcc}$ & $\left|\begin{array}{l}\text { 消費过るn } / 10 \\
\mathrm{KOHcc}\end{array}\right|$ & $\mathrm{CH}_{3} \mathrm{CO} \mathrm{mg}$ & $\mathrm{CH}_{3} \mathrm{CO} \%$ \\
\hline 9 & 24 & 0.0985 & $\begin{array}{c}0.891 \\
10\end{array}$ & F. $\begin{array}{l}1.091 \\
33.61\end{array}$ & 8.37 & 36.0 & 36.54 \\
\hline 10 & 48 & 0.1100 & $\begin{array}{c}\text { F. } 0.891 \\
10\end{array}$ & F. $\begin{array}{r}1.091 \\
32.29\end{array}$ & 9.32 & 40.1 & 36.43 \\
\hline 11 & 72 & 0.0996 & $\begin{array}{c}\text { F. } 0.891 \\
10\end{array}$ & F. $\begin{array}{r}1.091 \\
33.51\end{array}$ & 7.99 & 34.4 & 36.50 \\
\hline
\end{tabular}

第 VI 表

\begin{tabular}{|c|c|c|c|c|c|c|c|c|c|c|}
\hline 製 & 造 & 条 & 件 & \multicolumn{7}{|c|}{ アセチル基定量 } \\
\hline 番 号 & \multicolumn{3}{|c|}{2 回アセチル化 } & & 料 $\mathrm{g}$ & $\begin{array}{l}\text { アルュール性 } \\
\mathrm{n} / 2-\mathrm{KOHcc}\end{array}$ & $\mathrm{n} / 10-\mathrm{HCl} \mathrm{cc}$ & $\left|\begin{array}{l}\text { 洞費せるn } \mathrm{n} / 10 \\
\text { KOHcc }\end{array}\right|$ & $\mathrm{CH}_{3} \mathrm{COmg}$ & $\mathrm{CH}_{3} \mathrm{CO} \%$ \\
\hline 12 & 2 & を 原 & 料 & & .1105 & F. 0.891 & F. $\begin{array}{l}1.160 \\
30.40\end{array}$ & 9.29 & 40.0 & 36.15 \\
\hline 13 & 9 & を原 & 料 & & .0886 & $\begin{array}{c}\text { F. } 0.891 \\
10\end{array}$ & F. $\begin{array}{l}1.091 \\
33.91\end{array}$ & 7.55 & 32.5 & 36.65 \\
\hline
\end{tabular}

第 VII 袁

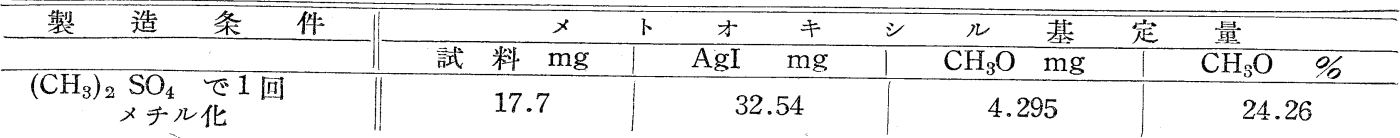




\begin{tabular}{|c|c|c|c|c|}
\hline 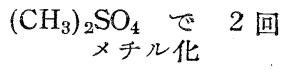 & 17.7 & 34.04 & 4.493 & 25.38 \\
\hline$\underset{\substack{\text { ×チル化 } \\
\left(\mathrm{CH}_{3}\right)_{2} \mathrm{SO}_{4}}}{ } 3$ 回 & 24.4 & 27.00 & 6.209 & 25.45 \\
\hline $\begin{array}{r}\left(\mathrm{CH}_{3}\right)_{2} \mathrm{SO}_{4} \text { で } \\
\text { メチル化 }\end{array}$ & 16.9 & 36.34 & 4.797 & 28.38 \\
\hline$\underset{\substack{\text { ×チル化 } \\
\left(\mathrm{CH}_{3}\right)_{2} \mathrm{SO}_{4}}}{5 \text { 回 }}$ & 10.1 & 22.44 & 2.962 & 29.33 \\
\hline 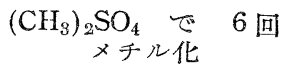 & 9.85 & 22.34 & 2.949 & 29.94 \\
\hline $\begin{array}{l}\left(\mathrm{CH}_{3}\right)_{2} \mathrm{SO}_{4} 6 \text { 回×テル } \\
\text { 化物を } \mathrm{CH}_{3} \mathrm{I} \text { エ゙チル化 }\end{array}$ & 9.20 & 19.74 & 2.606 & 28.32 \\
\hline
\end{tabular}

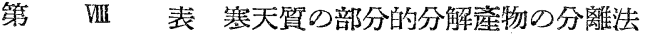

寒天質 $30 \mathrm{~g}$ r $600 \mathrm{cc} \odot d-\mathrm{H}_{2} \mathrm{SO}_{4}$ を加

元沸騰水浴上で一定時間加熱する。加染停

止時の溶液の還元力を湘定し 1 夜放置する

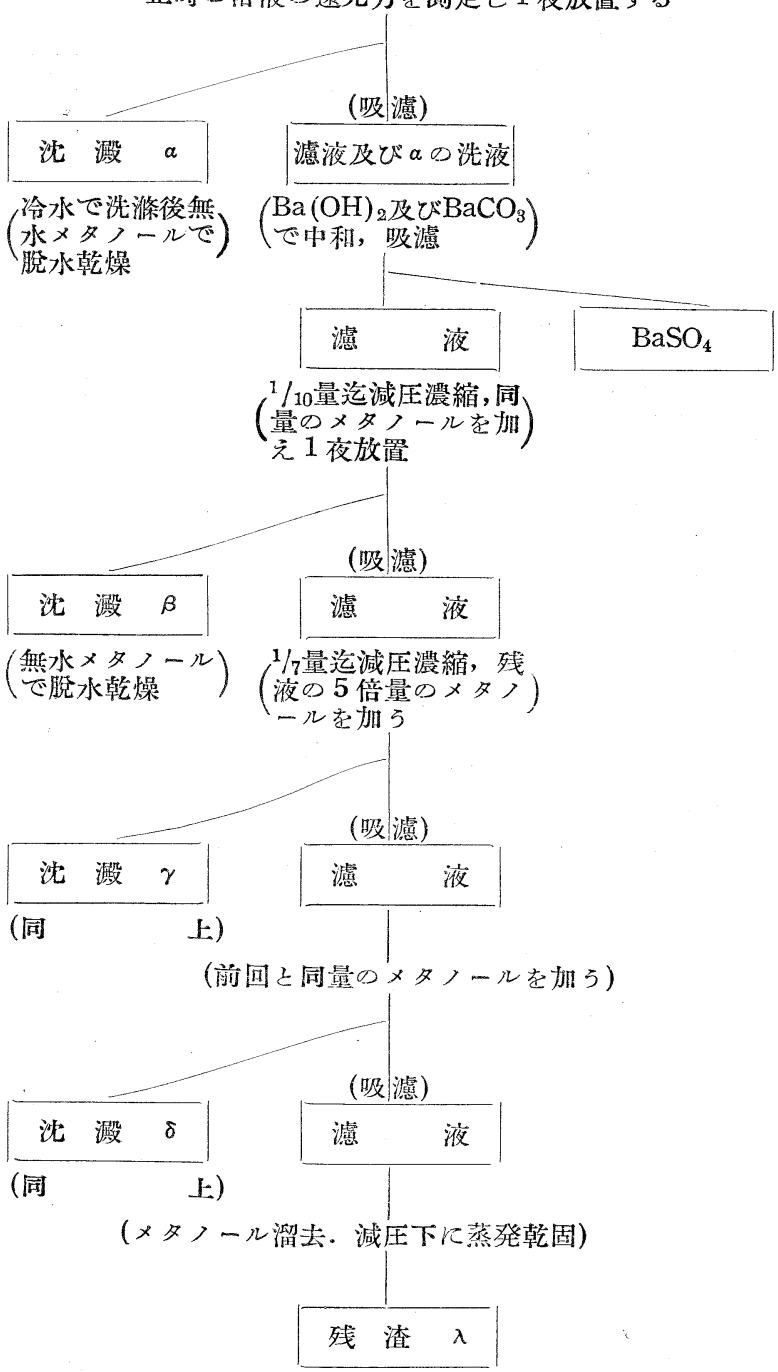

註；（）澡作を示す 
第 IX 表 寒天質の部分的分解產物の收量

\begin{tabular}{|c|c|c|c|c|c|c|c|c|}
\hline 䊩号 & 硫婹濃度 & $\begin{array}{c}\text { 加熱時間 } \\
(\text { 分 }) \\
\end{array}$ & $\left|\begin{array}{|c|}\text { 加熱停止時の } \\
\text { 還元力,註 2) }\end{array}\right|$ & $a \mathrm{~g}$ & $\beta \mathrm{g}$ & $\gamma \mathrm{g}$ & $\delta \mathrm{g}$ & $\lambda \mathrm{g}$ \\
\hline 1 & $\mathrm{n} / 50$ & 62 & $30 \mid$ & 7.0 & 0.7 & 9.0 & \multirow{2}{*}{$\begin{array}{c}0.8 \\
\text { 註3) } \\
-\end{array}$} & 4.0 \\
\hline 2 & $\mathrm{n} / 50$ & 50 & 17 & 10.5 & 0.8 & 6.5 & & 3.5 \\
\hline 3 & $\mathrm{n} / 50$ & 50 & 22 & 6.5 & 1.8 & 7.0 & 1.7 & 4.5 \\
\hline 4 & $\mathrm{n} / 100$ & 80 & 18 & 10.5 & - & 6.5 & 0.8 & 2.9 \\
\hline 5 & $\mathrm{n} / 100$ & 70 & 15 & 13.5 & - & 6.0 & - & 2.0 \\
\hline 6 & $\mathrm{n} / 100$ & 80 & 17.5 & 11.3 & - & 7.5 & - & 2.1 \\
\hline 7 & $\mathrm{n} / 100$ & 100 & 35 & 4.5 & - & 14.0 & - & - \\
\hline 計 & & & & 63.8 & 3.3 & 55.5 & 3.3 & 19.0 \\
\hline
\end{tabular}

註 2) 反應 $10 \mathrm{cc}$ 液中の還元傏の量を Bertrand 法で定量し galactose として表わした mg

証 3) 吸湿性强く梅雨期ですつたので分離出來なかつた

第 $\mathrm{X}$ 表 塞天質の部分的分解產物の分析値

\begin{tabular}{c|c|c|c|c|c}
\hline \hline & 還 元 力 $\%$ & 全還元榶 \% & galactose \% & $\mathrm{SO}_{3} \%$ & 分子量 \\
\hline 塞天質 & 0 & 73.05 & 29.11 & 0.57 & 11494 \\
$\alpha_{3}$ & 0 & 77.46 & 29.99 & 0.14 & 4032 \\
$\gamma_{3}$ & 4.78 & 67.31 & 36.33 & 0.56 & 2849 \\
$\delta_{3}$ & 9.89 & 68.92 & 39.03 & 0.20 & 2272 \\
$\lambda_{3}$ & 24.71 & 65.83 & - & - & 1481 \\
\hline
\end{tabular}

第 XI 表 寒天質の部分的分解謃物の沃素價及び分子量

\begin{tabular}{|c|c|c|c|c|c|}
\hline & 試 & 料 $\mathrm{g}$ & 消費した n/10 I cc & 沃素價 & 分子量 \\
\hline アセチル寒天質 & & 0.3208 & 0.56 & 1.74 & 11494 \\
\hline アセチル $\quad \alpha_{3}$ & & 0.4201 & 2.08 & 4.96 & 4032 \\
\hline アセチル $\gamma_{3}$ & & 0.3819 & 2.68 & 7.02 & 2849 \\
\hline アセチル $\quad \delta_{3}$ & & 0.2250 & 1.98 & 8.80 & 2272 \\
\hline アセチル $\lambda_{3}$ & & 0.1430 & 1.97 & 13.50 & 1481 \\
\hline
\end{tabular}

\section{Summary}

The agar substance from the agar preparation made from Gracilaria Confervoides Grev., was purified and chemically studied. It was hydrolyzed completedly with $1 N-$ $\mathrm{H}_{2} \mathrm{SO}_{4}$, and $d$-galactose isolated as crystals. By partial hydrolysis in a short period of time with $0.02 \mathrm{~N}$ - or $0.01 \mathrm{~N}-\mathrm{H}_{2} \mathrm{SO}_{4}$, five kinds of oligosaccharide were obtained whose analytical values and molecular weights were compared with those of the original agar substance. Acetyl- and methyl-agar were prepared and their properties were found to be very similar to those of agar substance obtained from Gelidium Amansii Lam ". However, complete methylation product of the former could not be obtained. The content of sulfuric acid was found to be much less in the agar from Gracilaria Confervoides than that from Gelidium Amansii. 